\title{
Comparative Evaluation of Soluble and Insoluble-Bound Phenolics and Antioxidant Activity of Two Chinese Mistletoes
}

\author{
Qing $\mathrm{Li}^{1}{ }^{1}$, Shihua Yang ${ }^{2}$, Yongqiang $\mathrm{Li}^{1, *}{ }^{10}$, Xiaofeng Xue $^{3, *}$, Yonghua Huang ${ }^{1}$, Hengguo Luo ${ }^{1}$, \\ Yiming Zhang ${ }^{1}$ and Zhichao $\mathrm{Lu}^{1}$ \\ 1 College of Food Science and Technology, Yunnan Agricultural University, Kunming 650201, China; \\ 13211674852@163.com (Q.L.); hyh209920@163.com (Y.H.); 115559818968@163.com (H.L.); \\ zym718zhangym@163.com (Y.Z.); luzhichao1s@163.com (Z.L.) \\ 2 College of Foreign Languages, Yunnan Agricultural University, Kunming 650201, China; \\ yanglifang815@163.com \\ 3 Institute of Apicultural Research, Chinese Academy of Agricultural Sciences, Beijing 100093, China \\ * Correspondence: liyongqiang7512@ynau.edu.cn (Y.L.); xue_xiaofeng@126.com (X.X.); \\ Tel.: +86-139-8761-1915 (Y.L.); +86-10-6259-4643 (X.X.)
}

Received: 31 December 2017; Accepted: 6 February 2018; Published: 8 February 2018

\begin{abstract}
Mistletoes are used medicinally in order to treat various human illnesses. Few studies have reported on the phenolic content and antioxidant properties of Chinese mistletoes (CMs). In this work, the total phenolic content (TPC), total flavonoid content (TFC), and antioxidant activities of soluble and insoluble-bound phenolic extracts from CMs hosted by Camellia assamica (Mast.) Chang (CMC) and Pyrus, i, f. (CMP) were compared. Phenolic compounds in CMC and CMP were identified and quantified using high-performance liquid chromatography (HPLC). The results indicated that the TPC of soluble phenolic extracts was higher than insoluble-bound phenolic counterparts in both CMC and CMP. In addition, the TPC of soluble, insoluble-bound and total phenolic fractions $(9.91 \pm 0.23,4.59 \pm 0.27$ and $14.50 \pm 0.35 \mu \mathrm{mol}$ ferulic acid equivalents per gram (FAE/g) dry sample) extracted from CMP were higher than those extracted from CMC. The soluble phenolic extracts in CMP showed higher antioxidant activities than those in CMC. Eighteen phenolic compounds from soluble and insoluble-bound phenolic extracts from the CMs were identified and quantified by HPLC. This study indicates that CMC and CMP, especially the latter, could be sources of antioxidants in human health care.
\end{abstract}

Keywords: Chinese mistletoes; phenolics; phenolic contents; antioxidant activity

\section{Introduction}

Mistletoes belonging to the order Santalales, which comprises Santalaceae, Loranthaceae, and Misodendraceae, are semi-parasites that grow on the Theaceae, Rosaceae, Moraceae and Leguminosae families [1]. Most are distributed in Southern and Central Asia, North-Western Africa, Europe and Eastern Australia [2-4]. Since ancient times, mistletoes have been applied as traditional medicines for the treatment of cancer and some chronic diseases due to their antioxidant and anti-inflammatory activities [3,5-7].

The main phytoconstituents, including proteins, carbohydrates, flavonoids, glycosides, phenolic compounds, tannins and triterpenes, have been identified in mistletoes by their physicochemical properties and spectral analysis [8-10]. In addition, several studies have revealed that mistletoes possess moderate antioxidant capacity due to the presence of phenolic compounds [9-11]. Viscum articulatum Burm. f. hosted by Camellia assamica (Mast.) Chang (CMC) and Viscum liquidambaricolum 
Hayata parasitic on Pyrus, $i, f$. (CMP) are two native Chinese mistletoes (CMs). CMC has been commonly used in traditional Chinese medicine for the treatment of hemorrhage, pleurisy, gout, heart disease, epilepsy, arthritis, and hypertension [12]. Previous investigations of CMC have revealed that phenolic glycosides, flavanone glycosides, triterpenoids, organic acids and flavonoids are the major secondary metabolites of this plant $[13,14]$. A few studies have focused on the phenolic composition and antioxidant activities of soluble phenolic compounds in CMC. However, there has been little research into insoluble-bound phenolic compounds in CMC. Moreover, the phenolic composition and antioxidant activities of CMP are unclear.

Phenolic compounds produced during secondary metabolism are characterized by some phenolic hydroxyl groups in the molecules [15]. These can be divided into several groups, including phenolic acids, flavonoids, stilbenes and lignans, based on the chemical structure of the phenolic compounds [16]. According to their solubility features, phenolics are separated into soluble and insoluble-bound fractions [17-19]. Insoluble-bound phenolics are covalently bound to the cell-wall matrix, including cellulose, arabinoxylans and proteins by ester, ether and carbon-carbon bonds [18]. Organic solvent is used to extract the soluble phenolic compounds, whereas acidic, alkaline or enzymatic hydrolysis are used to release insoluble-bound phenolics [19]. Insoluble-bound phenolics may be slowly and continuously released in the human gastrointestinal tract and during colonic fermentation, which can improve bioaccessibility and potential bioavailability and exert high bioactivity on tissues and cells for a long time $[18,20]$. However, most studies reported in the literature have ignored insoluble-bound phenolic compounds, and hence have underestimated their phenolic compound content and activities. Phenolic compounds are major sources of dietary antioxidants in the plants [21]. Antioxidants have beneficial health aspects, preventing and scavenging free radicals by means of donating hydrogen atoms to a free radical in order to protect biomolecules, such as proteins, lipids, carbohydrates and DNA [20,22,23], and to alleviate chronic diseases and degenerative ailments [24]. Thus, the beneficial effects of mistletoes may be attributed to their phenolic compounds [21].

The objectives of this study were to quantify the total phenolic and flavonoid contents of soluble and insoluble-bound phenolic extracts and to assess the antioxidant activities of CMC and CMP. The phenolic compounds in these two Chinese mistletoes were identified and quantified by high-performance liquid chromatography (HPLC). Moreover, the content, compositions and antioxidant activities of phenolic extracts in CMC and CMP were compared.

\section{Results and Discussion}

\subsection{Total Phenolic Content (TPC) and Total Flavonoid Content (TFC)}

Phenolics are the predominant group of phytochemical compounds, and are widely distributed in flowers, fruits, seeds, roots, stems, leaves of various plants and medicinal herbs [3,25,26]. Figure 1 presents the TPC and TFC of soluble and insoluble-bound phenolic extracts of CMC and CMP. The TPC of soluble, insoluble-bound and total phenolic extracts in CMs ranged from 8.65-9.91 $\mu \mathrm{mol}$ FAE/g DS, 3.95-4.59 $\mu \mathrm{mol} \mathrm{FAE/g} \mathrm{DS} \mathrm{and} \mathrm{12.59-14.50} \mathrm{\mu mol} \mathrm{FAE/g} \mathrm{DS,} \mathrm{respectively.} \mathrm{The} \mathrm{TPC} \mathrm{of} \mathrm{soluble} \mathrm{phenolic}$ extracts, either in CMC or in CMP, was significantly higher $(p<0.05)$ than that of insoluble-bound phenolic content. Similar results have been obtained for the TPC of millet, barley, onion and the different parts of Castanea crenata [22,26,27]. However, in contrast to the results obtained in the present works, some researchers have found that the TPC of soluble phenolic extracts was lower than insoluble-bound phenolics [28,29], which may be due to the differences of bond strength between phenolic compounds and cell-wall matrix. Moreover, the TPC of soluble, insoluble-bound and total phenolic in extracts of CMP were significantly higher than those in CMC $(p<0.05)$. 

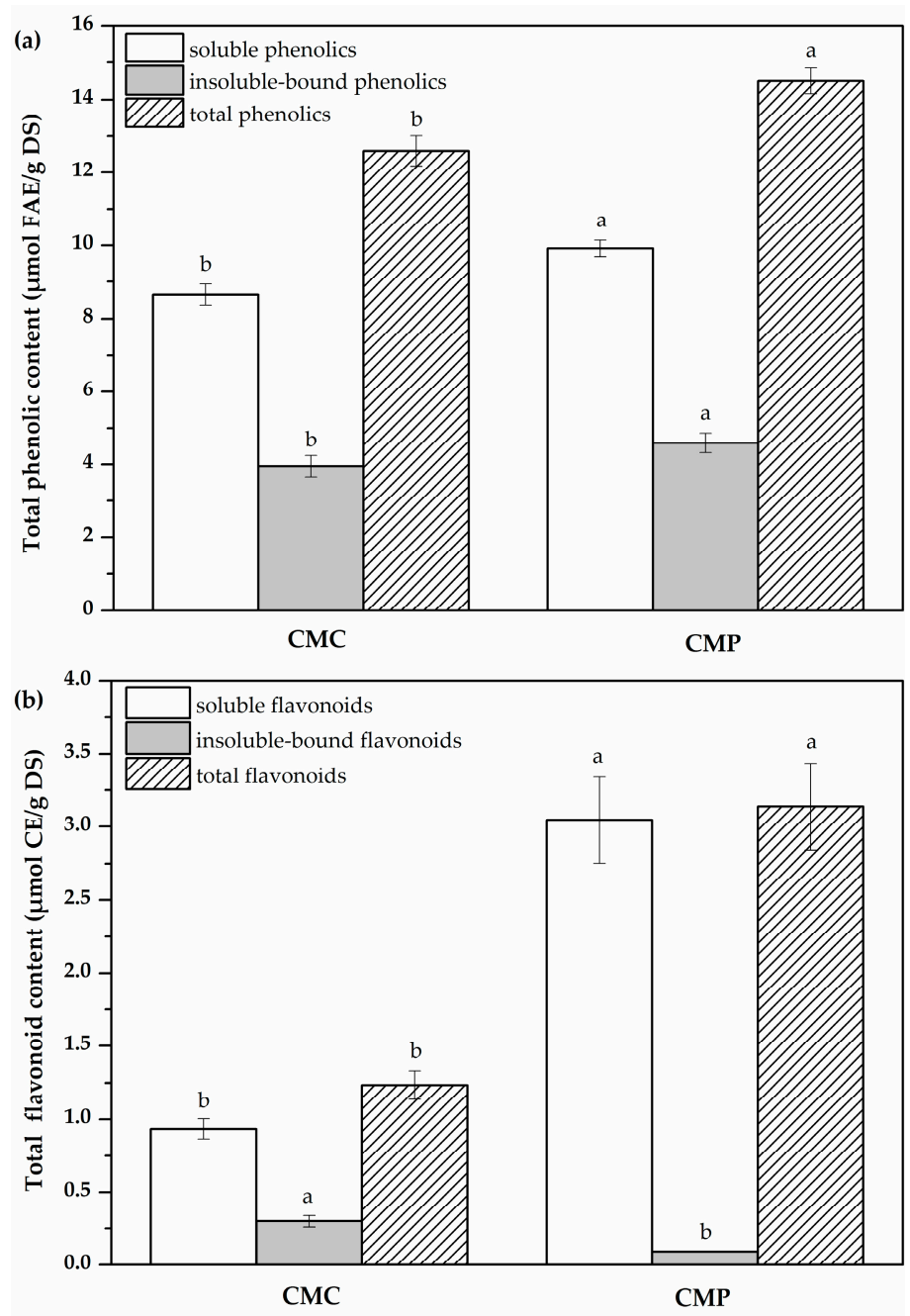

Figure 1. Total phenolic content (a) and flavonoid content (b) of soluble and insoluble-bound phenolic extracts in the two Chinese mistletoes (CMs). Different letters in each category (soluble, insoluble-bound, and total phenolics) are significantly different $(p<0.05)$. CMC, the Chinese mistletoes hosted by Camellia assamica (Mast.) Chang; CMP, the Chinese mistletoes hosted by Pyrus, $i, f$; FAE, ferulic acid equivalents; CE, catechin equivalents; DS, dry sample.

Flavonoids are phenolic compounds that exhibit various biological activities, such as anti-cancer, anti-allergenic, anti-viral, anti-inflammatory effects, vasodilating actions and gastroprotective properties, as well as having superior antioxidant activities [30]. The TFC of soluble, insoluble-bound and total flavonoids extracts in CMs ranged from 0.93-3.05 $\mu \mathrm{mol} \mathrm{CE} / \mathrm{g}$ DS, $0.10-0.30 \mu \mathrm{mol} \mathrm{CE} / \mathrm{g}$ DS and 1.23-3.14 $\mu \mathrm{mol} \mathrm{CE/g} \mathrm{DS,} \mathrm{respectively.} \mathrm{The} \mathrm{TFC} \mathrm{of} \mathrm{the} \mathrm{soluble} \mathrm{and} \mathrm{insoluble-bound} \mathrm{flavonoids}$ extracts in CMC and CMP exhibited a similar trend to that of TPC. The results showed that the TFC of the soluble flavonoids fractions in CMs was higher than corresponding insoluble-bound flavonoids. Similar results have been reported in previous studies [22,27]. The TFC of soluble flavonoid extracts in CMP was significantly higher $(p<0.05)$ than that in CMC. However, the TFC of insoluble-bound flavonoids extracts in CMC was significantly higher than that in CMP $(p<0.05)$. This discrepancy may be attributed to majority flavonoids that could bind the proteins and polysaccharides through ether and ester bonds in the CMC [18].

The results of our studies demonstrated that the TPC and TFC of both soluble and insoluble phenolic extracts were different in CMC and CMP. In addition, the TPC and TFC of total soluble phenolics in CMP were higher than those of in CMC. 


\subsection{Antioxidant Activities In Vitro}

The antioxidant capacities of phenolic extracts can be measured in several ways. In this study, four different and complementary methods (ferric reducing antioxidant power (FRAP), hydrogen peroxide scavenging activity (HPSA), DPPH radical scavenging activity (DRSA) and Trolox equivalent antioxidant capacity (TEAC)) were used to describe more fully the antioxidant capacities in vitro. Although these assays are of limited use in predicting health benefits in humans, and extrapolation to an in vivo situation is not possible, they may still be valuable as a screening method for predicting the antioxidant activities of phenolic compounds [31,32].

The antioxidant activities of the soluble and insoluble-bound phenolic compounds extracted in CMC and CMP were detected (Table 1). It has been reported that there is a correlation between antioxidant activities and total phenolic content in many plants $[9,15,25,26,33-35]$. The FRAP of soluble and insoluble-bound phenolic extracts in CMs ranged from 42.25-44.76 $\mu \mathrm{mol} \mathrm{FE/g} \mathrm{DS} \mathrm{and} \mathrm{8.07-10.31} \mu \mathrm{mol}$ FE/g DS. The HPSA of two phenolic extracts in CMs were in the range of 1429.34-1431.87 $\mu \mathrm{mol} \mathrm{FAE/g}$ DS and 1383.79-1231.67 $\mu \mathrm{mol} \mathrm{FAE/g} \mathrm{DS.} \mathrm{The} \mathrm{DRSA} \mathrm{and} \mathrm{TEAC} \mathrm{of} \mathrm{soluble} \mathrm{phenolic} \mathrm{extracts} \mathrm{in} \mathrm{CMs}$ ranged from 2.19-2.51 $\mu \mathrm{mol} \mathrm{FAE} / \mathrm{g}$ DS and 81.03-84.92 $\mu \mathrm{mol} \mathrm{TE/g} \mathrm{DS,} \mathrm{and} \mathrm{those} \mathrm{of} \mathrm{insoluble-bound}$ phenolics ranged from 1.51-1.83 $\mu \mathrm{mol}$ FAE/g DS and 5.78-1.40 $\mu \mathrm{mol}$ TE/g DS. The FRAP, HPSA, DRSA and TEAC of the soluble phenolic extracts in CMs were significantly higher than their insoluble-bound phenolic counterparts $(p<0.05)$. The same trends of antioxidant activities were observed in millet, barley and onion [22,27]. In addition, soluble phenolic extracts in CMP had higher antioxidant capacities in terms of FRAP, HPSA, DRSA and TEAC than those in CMC. However, it was found that insoluble-bound phenolic fractions in CMP had significantly higher FRAP and DRSA values than those in CMC $(p<0.05)$. Therefore, our results showed that CMP with higher phenolic and flavonoid contents had stronger antioxidant activities than CMC. Thus, the two CMs might be used as food additives because their phenolic extracts had good antioxidative and radical-scavenging activities.

Table 1. Antioxidant activities of the two Chinese mistletoes.

\begin{tabular}{|c|c|c|}
\hline Plant Material & CMC & CMP \\
\hline \multicolumn{3}{|c|}{ Ferric Reducing Antioxidant Power ( $\mu \mathrm{mol}$ FE/g DS) } \\
\hline Soluble & $42.25 \pm 1.49 \mathrm{a}^{2}$ & $44.76 \pm 0.32 \mathrm{a}^{1}$ \\
\hline Insoluble-bound & $8.07 \pm 0.75 b^{2}$ & $10.31 \pm 0.46 b^{1}$ \\
\hline \multicolumn{3}{|c|}{ Hydrogen Peroxide Scavenging Activity ( $\mu \mathrm{mol}$ FAE/g DS) } \\
\hline Soluble & $1429.34 \pm 7.69 \mathrm{a}^{1}$ & $1431.87 \pm 4.16 \mathrm{a}^{1}$ \\
\hline Insoluble-bound & $1383.79 \pm 3.33 b^{1}$ & $1231.67 \pm 12.23 b^{2}$ \\
\hline \multicolumn{3}{|c|}{ DPPH Radical Scavenging Activity ( $\mu \mathrm{mol}$ FAE/g DS) } \\
\hline Soluble & $2.19 \pm 0.11 \mathrm{a}^{2}$ & $2.51 \pm 0.04 \mathrm{a}^{1}$ \\
\hline Insoluble-bound & $1.51 \pm 0.07 \mathrm{~b}^{2}$ & $1.83 \pm 0.09 \mathrm{~b}^{1}$ \\
\hline \multicolumn{3}{|c|}{ Trolox Equivalent Antioxidant Capacity ( $\mu \mathrm{mol}$ TE/g DS) } \\
\hline Soluble & $81.03 \pm 0.90 \mathrm{a}^{2}$ & $84.92 \pm 1.50 \mathrm{a}^{1}$ \\
\hline Insoluble-bound & $5.78 \pm 1.24 \mathrm{~b}^{1}$ & $1.40 \pm 0.24 \mathrm{~b}^{2, *}$ \\
\hline
\end{tabular}

* $\mathrm{CMC}$, the Chinese mistletoes hosted by Camellia assamica (Mast.) Chang; CMP, the Chinese mistletoes hosted by Pyrus, i, f.; FE, $\mathrm{Fe}^{2+}$ equivalents; FAE, ferulic acid equivalents; TE, Trolox equivalents; DS, dry sample. Values are mean \pm standard deviation $(n=5)$; Values in each row having the different superscripts are significantly different $(p<0.05)$; values in each column having the different letter values are significantly different $(p<0.05)$.

\subsection{Identification and Quantification of the Two Chinese Mistletoe (CM) Extracts by High-Performance Liquid Chromatography (HPLC)}

The HPLC chromatograms of soluble and insoluble-bound phenolic compounds in CMC and CMP extracts are presented in Figures 2 and 3. The main classes of phenolic compounds identified in $\mathrm{CMC}$ and CMP were hydroxybenzoic acids, hydroxycinnamic acids and flavonoids.

The phenolic compounds of soluble phenolic extracts are shown in Table 2. Several hydroxybenzoic acids, including gallic acid, protocatechuic acid, $p$-hydroxybenzoic acid, vanillic acid, syringic acid 
and vanillin, were identified in CMC and CMP by comparison of their retention time (RT) with those of the available standards (Figure S1). Our results showed that the RT of phenolic compounds of hydroxybenzoic acids in CMP were 1.95-5.88 times higher than those in CMC, except for vanillic acid and syringic acid. The major hydroxycinnamic acids identified were chlorogenic acid, caffeic acid, $p$-coumaric acid, ferulic acid and trans-cinnamic acid. In general, the RT of caffeic acid, $p$-coumaric acid and trans-cinnamic acid in CMP were 1.12, 9.64 and 2.54 times higher than those in CMC. Flavonoids, namely catechin hydrate, epicatechin, (-)-epigallocatechin, myricetin, quercetin, kaempferol and apigenin were determined. Flavonoids are a large family of compounds in plants [30]. The content of all six phenolic compounds in CMP was higher than those in CMC. In addition, our results showed that myricetin $(2209.79 \pm 1476.96 \mu \mathrm{g} / \mathrm{g})$ and epicatechin $(238.18 \pm 79.30 \mu \mathrm{g} / \mathrm{g})$ were the most abundant in CMP and CMC, respectively. Previous research has shown that quercetin was the most abundant among five Polish Viscum album [9]. The difference between Polish Viscum album and CMs may be due to the varieties and the growth conditions of the plants. In addition, flavonoids constituted a substantial content of total phenolic compounds and individually contributed to $24.55 \%$ and $60.94 \%$ of the content in CMC and CMP, respectively. Vanillic acid $(1325.77 \pm 23.34 \mu \mathrm{g} / \mathrm{g})$ and myricetin $(2209.79 \pm 1476.96 \mu \mathrm{g} / \mathrm{g})$ might be characteristic phenolic compounds in CMC and CMP, respectively, due to their high contents. Most of the eighteen phenolic compounds were also found in different mistletoes $[9,14,36]$. Furthermore, myricetin had been recognized as a source that could limit type 2 diabetes mellitus [37]. Hence, the phenolic compounds of CMs have potential to be researched further. The insoluble-bound phenolic profiles are given in Table 3. Eighteen phenolic compounds subdivided into hydroxybenzoic acids, hydroxycinnamic acid and flavonoids, were also identified and quantified by HPLC. Moreover, $p$-coumaric acid $(206.97 \pm 21.39 \mu \mathrm{g} / \mathrm{g})$ and (-)-epigallocatechin $(223.32 \pm 24.87 \mu \mathrm{g} / \mathrm{g})$ might be characteristic phenolic compounds in insoluble-bound phenolic extracts of CMC and CMP, respectively.

Table 2. Individual soluble phenolic compounds in the two Chinese mistletoes ( $\mu \mathrm{g} / \mathrm{g}$ DS sample).

\begin{tabular}{ccc}
\hline Phenolic Compounds & CMC & CMP \\
\hline \multicolumn{3}{c}{ Hydroxybenzoic Acids } \\
\hline Gallic acid & $67.51 \pm 12.21$ & $172.65 \pm 4.34$ \\
Protocatechuic acid & $39.65 \pm 9.27$ & $203.23 \pm 12.89$ \\
$p$-Hydroxybenzoic acid & $133.88 \pm 116.31$ & $787.95 \pm 138.89$ \\
Vanillic acid & $1325.77 \pm 23.34$ & $408.82 \pm 29.21$ \\
Syringic acid & $432.33 \pm 370.24$ & $66.68 \pm 27.90$ \\
Vanillin & $70.08 \pm 36.40$ & $136.92 \pm 130.03$ \\
Total & 2069.23 & 1776.25 \\
\hline \multicolumn{3}{c}{ Hydroxycinnamic Acids } \\
\hline Chlorogenic acid & $93.36 \pm 50.71$ \\
Caffeic acid & $105.59 \pm 12.03$ & $68.85 \pm 27.70$ \\
$p$-Coumaric acid & $85.05 \pm 70.36$ & $119.18 \pm 16.77$ \\
Ferulic acid & $560.48 \pm 25.71$ & $248.10 \pm 355.68$ \\
trans-Cinnamic acid & $67.80 \pm 9.00$ & $172.60 \pm 1.93$ \\
Total & 912.28 & 1429.55 \\
& Flavonoids \\
\hline Catechin hydrate & $188.60 \pm 138.25$ \\
Epicatechin & $238.18 \pm 79.30$ \\
(-)-Epigallocatechin & $237.03 \pm 8.36$ & $200.51 \pm 150.87$ \\
Myricetin & $154.88 \pm 62.10$ & $569.53 \pm 67.92$ \\
Quercetin & $85.22 \pm 28.75$ & $542.10 \pm 23.71$ \\
Kaemferol & $40.48 \pm 10.23$ & $834.71 \pm 1476.96$ \\
Apigenin & $25.50 \pm 5.66$ & $447.18 \pm 3.19$ \\
Total & 969.89 & $5001.44 *$ \\
\hline
\end{tabular}

* CMC: the Chinese mistletoes hosted by Camellia assamica (Mast.) Chang; CMP: the Chinese mistletoes hosted by Pyrus, $i, f$; Values are mean \pm standard deviation $(n=3)$. 
Table 3. Individual insoluble-bound phenolic compounds in the two Chinese mistletoes ( $\mu \mathrm{g} / \mathrm{g}$ DS sample).

\begin{tabular}{ccc}
\hline Phenolic Compounds & CMC & CMP \\
\hline \multicolumn{3}{c}{ Hydroxybenzoic Acids } \\
\hline Gallic acid & $6.34 \pm 0.56$ & $21.41 \pm 0.92$ \\
Protocatechuic acid & $27.43 \pm 1.73$ & $23.24 \pm 4.45$ \\
p-Hydroxybenzoic acid & $48.02 \pm 22.44$ & $55.20 \pm 42.12$ \\
Vanillic acid & $52.73 \pm 8.40$ & $37.40 \pm 25.69$ \\
Syringic acid & $6.39 \pm 1.14$ & $10.45 \pm 6.34$ \\
Vanillin & $13.18 \pm 7.35$ & $39.69 \pm 2.06$ \\
Total & 154.08 & 187.40 \\
\hline \multicolumn{3}{c}{ Hydroxycinnamic Acids } \\
\hline Chlorogenic acid & $12.28 \pm 2.43$ \\
Caffeic acid & $49.88 \pm 2.41$ & $22.21 \pm 12.98$ \\
p-Coumaric acid & $206.97 \pm 21.39$ \\
Ferulic acid & $97.94 \pm 4.63$ & $14.26 \pm 1.19$ \\
trans-Cinnamic acid & $43.06 \pm 1.02$ & $171.18 \pm 4.88$ \\
Total & 410.12 & $124.38 \pm 2.31$ \\
& Flavonoids & 360.23 \\
\hline Catechin hydrate & $129.17 \pm 32.41$ \\
Epicatechin & $11.21 \pm 9.76$ \\
(-)-Epigallocatechin & $14.63 \pm 10.29$ & $26.34 \pm 12.67$ \\
Myricetin & $33.14 \pm 19.55$ & $75.23 \pm 49.31$ \\
Quercetin & $41.44 \pm 11.71$ & $62.30 \pm 31.66$ \\
Kaemferol & $18.15 \pm 12.05$ & $99.40 \pm 69.46$ \\
Apigenin & $10.35 \pm 9.34$ & $9.33 \pm 6.64$ \\
Total & 258.10 & $588.13 *$ \\
\hline
\end{tabular}

* CMC: the Chinese mistletoes hosted by Camellia assamica (Mast.) Chang; CMP: the Chinese mistletoes hosted by Pyrus, $i, f$.; Values are mean \pm standard deviation $(n=3)$.
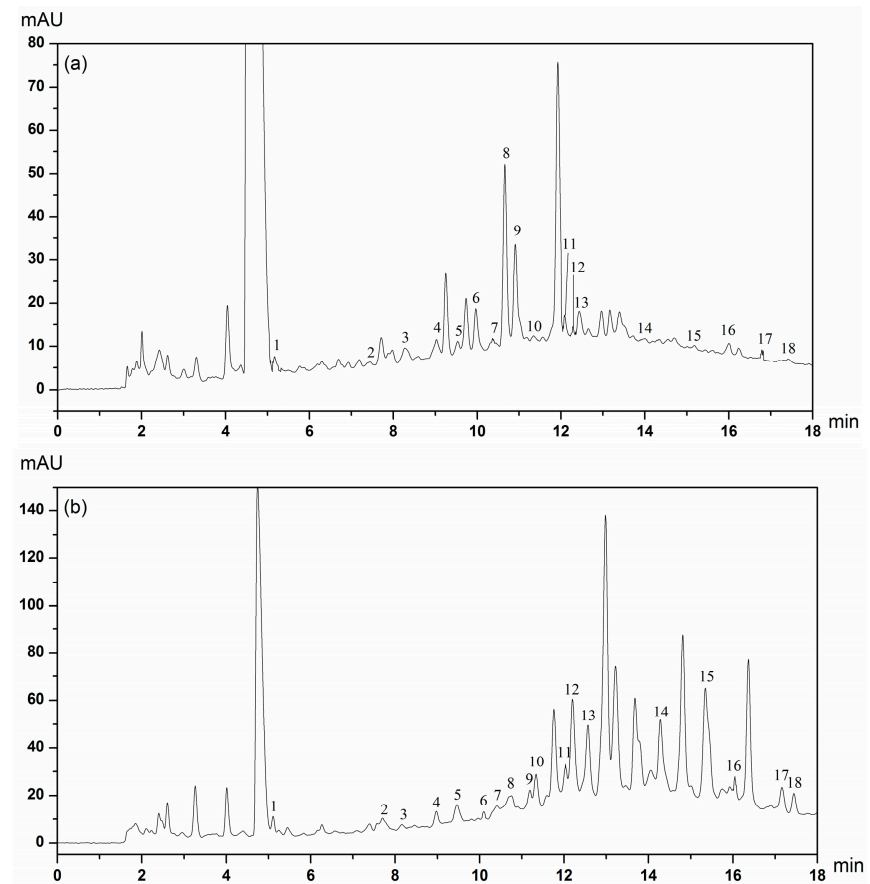

Figure 2. HPLC chromatograms of soluble phenolic extracts of the Chinese mistletoes hosted by Camellia assamica (Mast.) Chang (CMC) (a) and Pyrus, i, f. (CMP) (b). The identified compounds: 1, Gallic acid; 2, Protocatechuic acid; 3, Catechin hydrate; 4, Chlorogenic acid; 5, p-Hydroxybenzoic acid; 6, Epicatechin; 7, Caffeic acid; 8, Vanillic acid; 9, Syringic acid; 10 Vanillin; 11, (-)-Epigallocatechin; 12, p-Coumaric acid; 13, Ferulic acid; 14, Myricetin; 15, Quercetin; 16, trans-Cinnamic acid; 17, Kaempferol; 18, Apigenin. 

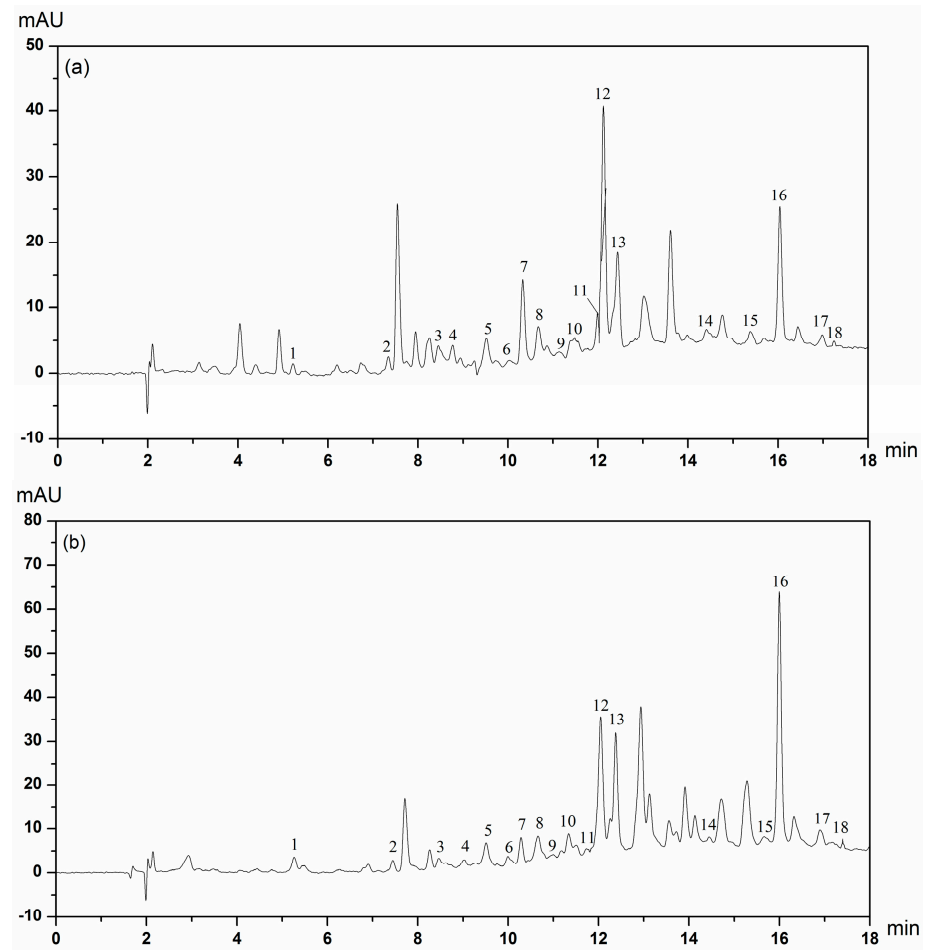

Figure 3. HPLC chromatograms of insoluble-bound phenolic extracts of the Chinese mistletoes hosted by Camellia assamica (Mast.) Chang (CMC) (a) and Pyrus, i, f. (CMP) (b). The identified compounds: 1, Gallic acid; 2, Protocatechuic acid; 3, Catechin hydrate; 4, Chlorogenic acid; 5, $p$-Hydroxybenzoic acid; 6, Epicatechin; 7, Caffeic acid; 8, Vanillic acid; 9, Syringic acid; 10 Vanillin; 11, (-)-Epigallocatechin; 12, p-Coumaric acid; 13, Ferulic acid; 14, Myricetin; 15, Quercetin; 16, trans-Cinnamic acid; 17, Kaempferol; 18, Apigenin.

\section{Materials and Methods}

\subsection{Materials and Chemical Reagent}

Viscum articulatum Burm. f. (CMC) and Viscum liquidambaricolum Hayata (CMP) were purchased from Pu'er, Yunnan province, China in 2016. Standard phenolic compounds (gallic acid, protocatechuic acid, chlorogenic acid, caffeic acid, $p$-coumaric acid, (-)-epigallocatechin, myricetin, kaempferol, apigenin, epicatechin, quercetin, vanillic acid, syringic acid, trans-cinnamic acid, catechin, ferulic acid, $p$-hydroxybenzoic acid and vanillin) were purchased from Beijing Beina Chuanglian Biotechnology Institute (Beijing, China). Folin-Ciocalteu phenol reagent, 6-hydroxy-2,5,7,8-tetramethylchroman2-carboxylic acid (Trolox), 2,2-diphenyl-1-picrylhydrazyl (DPPH) were obtained from Sigma-Aldrich (St. Louis, MO, USA). 2,4,6-Tripyridyl-s-triazine (TPTZ), 2,2'-azinobis (3-ethylbenzothiazoline6-sulfonic acid) (ABTS), trichloroacetic acid, ferric chloride, ascorbic acid, ferrous sulfate, potassium ferricyanide, sodium phosphate dibasic, sodium phosphate monobasic dihydrate, $\mathrm{H}_{2} \mathrm{O}_{2}$, aluminum chloride and potassium persulfate were purchased from Aladdin Industrial Corporation (Shanghai, China). HPLC-grade methanol and formic acid were purchased from Merck (Darmstadt, Germany). All chemicals used in the experiments were of analytical grade.

\subsection{Separation of Phenolic Compounds}

The soluble and insoluble-bound phenolic compounds from the two CMs were prepared using the methods reported in literature [20,38] with slight modifications. The mistletoes were ground to a fine powder with a Wiley mill (1029-A, Yoshida Seisakusho Co., Tokyo, Japan) for herbal medicine, and screened through a 50-mesh sieve. After the powder was freeze-dried with a vacuum freeze 
dryer (LGJ-12, Zhengzhou Nanbei Instrument Equipment Co., Ltd., Zhengzhou, China), $40 \mathrm{~mL}$ of $70 \%(v / v)$ acetone was added to $2.0 \mathrm{~g}$ of the dried powder, and then samples were shaken in an ultrasonic bath (SB-3200D, Ningbo Xinzhi biological Polytron Technologies Inc. 300 W, Ningbo, China) at room temperature for $15 \mathrm{~min}$. The mixture was centrifuged at $4000 \times \mathrm{g}$ for $10 \mathrm{~min}$ at $4{ }^{\circ} \mathrm{C}$ (TGL20M, Hunan Xiang Li Scientific Instrument Co., Ltd. Hunan, China). The upper layer was collected, and the extractions were repeated twice. The supernatants were combined and evaporated under reduced pressure at $30{ }^{\circ} \mathrm{C}$ (RE-52 AA, Shanghai Yarong biochemical instrument factory, Shanghai, China). This extract solution was analyzed as soluble phenolic extract.

The residues were used to extract the insoluble-bound phenolics. The samples were subsequently hydrolyzed with $40 \mathrm{~mL} \mathrm{NaOH}(4 \mathrm{~mol} / \mathrm{L})$ at ambient temperature under nitrogen gas for $4 \mathrm{~h}$. The resultant hydrolysate was acidified to $\mathrm{pH} 2$ using $\mathrm{HCl}(6 \mathrm{~mol} / \mathrm{L})$ and then centrifuged at $4000 \times \mathrm{g}$ for $10 \mathrm{~min}$ at $4{ }^{\circ} \mathrm{C}$. The supernatants were combined and extracted 3 times with an equal volume of diethyl ether and ethyl acetate at 1:1 $(v / v)$, and then evaporated under reduced pressure $\left(30^{\circ} \mathrm{C}\right)$. The insoluble-bound phenolic compounds were obtained. All samples were dissolved in $25 \mathrm{~mL}$ of HPLC grade methanol, and stored at $-20^{\circ} \mathrm{C}$ under nitrogen gas and covered with aluminum foil until used.

\subsection{Determination of TPC}

The TPC was determined using Folin-Ciocalteu phenol reagent, followed by the Chandrasekara and Shahidi [20] and Singleton and Rossi [39] methods, with slight modifications. Briefly, $500 \mu \mathrm{L}$ of each phenolic extract was added to $0.5 \mathrm{~mL}$ Folin-Ciocalteu phenol reagent $(2 \mathrm{~mol} / \mathrm{L})$ and $1 \mathrm{~mL}$ of saturated sodium carbonate $(75 \mathrm{~g} / \mathrm{L}$ ). After adding distilled water (to a total volume of $10 \mathrm{~mL}$ ) and thorough mixing, the mixture was allowed to stand at ambient temperature in the dark for $35 \mathrm{~min}$ and centrifuged at $4000 \times g$ for $10 \mathrm{~min}$ at $4{ }^{\circ} \mathrm{C}$. The absorbance of this solution versus a prepared blank was measured at $760 \mathrm{~nm}$. The content of total phenolics in each sample was determined using a standard curve prepared for ferulic acid and expressed as micromoles $(\mu \mathrm{mol})$ of ferulic acid equivalents (FAE) per gram of dry sample (DS) ( $\mu \mathrm{mol} \mathrm{FAE/g} \mathrm{DS).}$

\subsection{Determination of TFC}

The TFC was measured using the aluminum chloride colorimetric method as described by Kern et al. [40] and Chandrasekara and Shahidi [41], with slight modifications. Briefly, $2 \mathrm{~mL}$ of each phenolic extract was added to $4 \mathrm{~mL}$ of distilled water and $0.3 \mathrm{~mL}$ of $5 \% \mathrm{NaNO}_{2}$. Five minutes later, $0.3 \mathrm{~mL}$ of $10 \% \mathrm{AlCl}_{3}$ was added to the reaction mixture and allowed to react for $1 \mathrm{~min}$. Finally, $2 \mathrm{~mL}$ of $1 \mathrm{~mol} / \mathrm{L} \mathrm{NaOH}$ and $1.4 \mathrm{~mL}$ of distilled water were added and mixed as quickly as possible. The mixture was centrifuged at $4000 \times \mathrm{g}$ for $5 \mathrm{~min}$ at $4{ }^{\circ} \mathrm{C}$ after incubation at ambient temperature in the dark for $15 \mathrm{~min}$. The absorbance of this solution versus a prepared blank was measured at $510 \mathrm{~nm}$. Catechin was used as a reference standard, and the results were expressed as $\mu \mathrm{mol}$ of catechin equivalents (CE) per gram of dry sample ( $\mu \mathrm{mol} \mathrm{CE/g} \mathrm{DS).}$

\subsection{Determination of Ferric Reducing Antioxidant Power (FRAP)}

The FRAP method was based on the procedure described by Benzie and Strain [42] and Villanueva-Carvajal et al. [43], with slight modifications. Briefly, the FRAP working solution was prepared from acetate buffer ( $300 \mathrm{mmol} / \mathrm{L}, \mathrm{pH} 3.6), \mathrm{FeCl}_{3}$ solution $(20 \mathrm{mmol} / \mathrm{L})$, and 2,4,6-tripyridyls-triazine $(10 \mathrm{mmol} / \mathrm{L})$ in a volume ratio of 1:1:1. The phenolic extracts $(100 \mu \mathrm{L})$ were mixed with $3 \mathrm{~mL}$ of the FRAP working solution and incubated at $37^{\circ} \mathrm{C}$ in the dark for $4 \mathrm{~min}$. The absorbance of the solution was measured at $539 \mathrm{~nm}$. Ferrous sulfate was used as a reference standard, and the FRAP was expressed as $\mu \mathrm{mol}$ of $\mathrm{Fe}^{2+}$ equivalents (FE) per gram of dry sample ( $\mu \mathrm{mol} \mathrm{FE/g} \mathrm{DS).}$

\subsection{Determination of $\mathrm{H}_{2} \mathrm{O}_{2}$ Scavenging Activity (HPSA)}

The HPSA was measured by using the method described by Wettasinghe and Shahidi [44] and Chandrasekara et al. [41], with slight modifications. Briefly, the phenolic extracts $(600 \mu \mathrm{L})$ mixed with 
$0.9 \mathrm{~mL}$ of $\mathrm{H}_{2} \mathrm{O}_{2}(40 \mathrm{mmol} / \mathrm{L})$ and $1.5 \mathrm{~mL}$ of sodium phosphate buffer $(45 \mathrm{mmol} / \mathrm{L}, \mathrm{pH} 7.4)$, and the resulting solution was left to stand at $30{ }^{\circ} \mathrm{C}$ in the dark for $40 \mathrm{~min}$. Then, the absorbance of the solution was measured at $230 \mathrm{~nm}$. The HPSA was calculated using the following formula:

$$
\operatorname{HPSA}(\%)=\left[\left(c-c_{b}\right)-\left(s-s_{b}\right)\right] /\left(c-c_{b}\right) \times 100 \%
$$

where $c$ is absorbance of the $\mathrm{H}_{2} \mathrm{O}_{2}$ with the PBS, $c_{b}$ is absorbance of the PBS, $s$ is absorbance of the sample and the $\mathrm{H}_{2} \mathrm{O}_{2}$ with the PBS and $s_{b}$ is absorbance of the sample and the PBS. Ferulic acid dissolved in methanol was used to prepare the standard curve, the HPSA was expressed as $\mu \mathrm{mol}$ of FAE per gram of dry sample ( $\mu$ mol FAE/g DS).

\subsection{Determination of DPPH Radical Scavenging Activity (DRSA)}

The determination of the effect of extracts on DRSA was based on a procedure as determined by Hatano et al. [45] and Villanueva-Carvajal et al. [43], with slight modifications. Briefly, $1 \mathrm{~mL}$ of the phenolic extract was mixed with $4 \mathrm{~mL} 79 \mu \mathrm{mol} / \mathrm{L}$ methanolic DPPH solution and shaken vigorously. Absorbance was measured at $517 \mathrm{~nm}$ after the solution was incubated in the dark at ambient temperature for $10 \mathrm{~min}$. The radical scavenging activity was calculated using the following formula:

$$
\operatorname{DRSA}(\%)=\left[\left(c-c_{b}\right)-\left(s-s_{b}\right)\right] /\left(c-c_{b}\right) \times 100 \%
$$

where $c$ is absorbance of the DPPH solution, $c_{b}$ is absorbance of the methanol, $s$ is absorbance of the DPPH solution with the sample, and $s_{b}$ is absorbance of the methanol with the sample. The standard curve was prepared using ferulic acid and expressed as $\mu \mathrm{mol}$ of FAE per gram of dry sample ( $\mu \mathrm{mol} \mathrm{FAE/g} \mathrm{DS).}$

\subsection{Determination of Trolox Equivalent Antioxidant Capacity (TEAC)}

The TEAC of the extracts was determined as described by Re et al. [46], with slight modifications. Briefly, $100 \mu \mathrm{L}$ of phenolic extract was mixed in $3.8 \mathrm{~mL}$ ABTS working solution $(7 \mathrm{mmol} / \mathrm{L}$ ABTS mixed with $2.45 \mathrm{mmol} / \mathrm{L}$ potassium persulfate in a volume ratio of 1:1). The absorbance at $734 \mathrm{~nm}$ was measured in the dark for $6 \mathrm{~min}$. The TEAC was calculated using the following formula:

$$
\operatorname{TEAC}(\%)=\left[\left(c-c_{b}\right)-\left(s-s_{b}\right)\right] /\left(c-c_{b}\right) \times 100 \%
$$

where $c$ is absorbance of the ABTS working solution, $c_{b}$ is absorbance of the ethanol, $s$ is absorbance of the sample with the ABTS working solution, and $s_{b}$ is absorbance of the sample with the ethanol. Trolox was used as a reference standard, and the TEAC was expressed as $\mu \mathrm{mol}$ of Trolox equivalents (TE) per gram of dry sample ( $\mu \mathrm{mol} \mathrm{TE} / \mathrm{g} \mathrm{DS})$.

\subsection{HPLC Analysis}

All the phenolic fractions were injected into a high-performance liquid chromatography (HPLC) system (Agilent Technologies, Palo Alto, CA, USA) equipped with a G1315B diode array detector (DAD) and a G1316A column compartment. The separation was performed on a $150 \mathrm{~mm} \times 4.6 \mathrm{~mm}$, $5 \mu \mathrm{m}$ Agilent Zorbax SB-C18 at $30^{\circ} \mathrm{C}$. Its system controller was linked to a ChemStation for LC 3D systems (Agilent Technologies). The mobile phase consisted of methanol (Solvent A) and water with $0.5 \%$ formic acid (Solvent $\mathrm{B}$ ). The flow rate was maintained at $0.8 \mathrm{~mL} / \mathrm{min}$. The gradient program was as follows: 0 min, A:B (5:95, v/v); $20 \mathrm{~min}, \mathrm{~A}: \mathrm{B}(95: 5, v / v) ; 21 \mathrm{~min}, \mathrm{~A}: \mathrm{B}(5: 95, v / v)$; and $25 \mathrm{~min}, \mathrm{~A}: \mathrm{B}(5: 95$, $v / v$ ). The detect wavelength was set at $280 \mathrm{~nm}$. Identification and quantification of the 18 phenolic compounds were based on the RT and characteristic absorption spectrum from the DAD with those of their authentic standards. The quantitation of each phenolic compound was carried out using an external standard method. Available pure known compounds as external standards were used for quantifying samples. 


\subsection{Statistical Analysis}

All the analyses were performed, and the results were expressed as the mean \pm the standard deviation of three replicates. An independent-sample $t$-test was performed to determine differences between the two kinds of CM extracts at $p<0.05$. Statistical analysis was undertaken using SPSS version 22.0 software (SPSS Inc., Chicago, IL, USA).

\section{Conclusions}

The phenolic compounds and antioxidant activities of phenolic extracts in CMP were firstly studied. Moreover, the content, antioxidant activities and phenolic compounds of soluble and insoluble-bound phenolic extracts in CMC and CMP were also compared. The results of this study showed that the TPC and TFC of soluble phenolic extracts were higher than insoluble-bound phenolic extracts in both CMC and CMP. In addition, the TPC of soluble, insoluble-bound and total phenolic compounds in CMP were significantly higher than those in CMC $(p<0.05)$. The soluble phenolic extracts in CMP showed higher antioxidant activities than those in CMC. Eighteen phenolic compounds from phenolic extracts in these two CMs were identified and quantified by HPLC, respectively. Vanillic acid $(1325.77 \pm 23.34 \mu \mathrm{g} / \mathrm{g})$ and myricetin $(2209.79 \pm 1476.96 \mu \mathrm{g} / \mathrm{g})$ might be characteristic phenolic compounds in soluble phenolic extracts of CMC and CMP. The phenolic compounds of these two CMs represent a potential source of antioxidants. Therefore, CMC and CMP, especially the latter, may play an important role in human health. It is necessary to explore and possibly promote their use as functional food additives.

Supplementary Materials: Supplementary materials are available online. Figure S1. HPLC chromatograms of 18 phenolic standard samples.

Acknowledgments: This project was supported by the National Natural Science Foundation of China (Project No. 31360378, No. 31560428).

Author Contributions: Y.L. and X.X. designed the experiment scheme. Y.H., H.L., Y.Z. and Z.L. performed the experiments. Q.L. analyzed the data and wrote the paper. S.Y. critically revised the manuscript. X.X. was responsible for the analysis of chromatography. All authors made important contributions to the manuscript and approved the final version.

Conflicts of Interest: The authors declare no conflict of interest.

\section{References}

1. Nickrent, D.L. Santalales (Including Mistletoes). In Encyclopedia of Life Sciences; John Wiley \& Sons, Ltd.: Chichester, UK, 2011. [CrossRef]

2. Nazaruk, J.; Orlikowski, P. Phytochemical profile and therapeutic potential of Viscum album L. Nat. Prod. Res. 2015, 30, 373-385. [CrossRef] [PubMed]

3. Simirgiotis, M.J.; Quispe, C.; Areche, C.; Sepúlveda, B. Phenolic Compounds in Chilean Mistletoe (Quintral, Tristerix tetrandus) Analyzed by UHPLC-Q/Orbitrap/MS/MS and Its Antioxidant Properties. Molecules 2016, 21, 245-259. [CrossRef] [PubMed]

4. Molnár, A.; Végvári, Z. Bioclimatic constrains of European Mistletoe Viscum album at its southern distribution limit on past and present temporal scales, Pannon region, Hungary. Clim. Res. 2017, 71, 237-248. [CrossRef]

5. Yoo, J.M.; Yang, J.H.; Kim, Y.S.; Yang, H.J.; Cho, W.K.; Ma, J.Y. Inhibitory Effects of Viscum coloratum Extract on $\mathrm{IgE} /$ Antigen-Activated Mast Cells and Mast Cell-Derived Inflammatory Mediator-Activated Chondrocytes. Molecules 2017, 22, 37. [CrossRef] [PubMed]

6. Lim, Y.C.; Rajabalaya, R.; Lee, S.H.F.; Tennakoon, K.U.; Le, Q.V.; Idris, A.; Zulkipli, I.N.; Keasberry, N.; David, S.R. Parasitic Mistletoes of the Genera Scurrula and Viscum: From Bench to Bedside. Molecules 2016, 21, 1048-1081. [CrossRef] [PubMed]

7. Ma, Y.H.; Cheng, W.Z.; Gong, F.; Ma, A.L.; Yu, Q.W.; Zhang, J.Y.; Hu, C.Y.; Chen, X.H.; Zhang, D.Q. Active Chinese mistletoe lectin- 55 enhances colon cancer surveillance through regulating innate and adaptive immune responses. World J. Gastroenterol. 2008, 14, 5274-5281. [CrossRef] [PubMed] 
8. Patel, B.P.; Singh, P.K. Viscum articulatum Burm. f.: A review on its phytochemistry, pharmacology and traditional uses. J. Pharm. Pharmacol. 2017. [CrossRef] [PubMed]

9. Pietrzak, W.; Nowak, R.; Gawlik-Dziki, U.; Lemieszek, M.K.; Rzeski, W. LC-ESI-MS/MS Identification of Biologically Active Phenolic Compounds in Mistletoe Berry Extracts from Different Host Trees. Molecules 2017, 22, 624. [CrossRef] [PubMed]

10. Luczkiewicz, M.; Cisowski, W.; Kaiser, P.; Ochocka, R.; Piotrowski, A. Comparative analysis of phenolic acids in mistletoe plants from various hosts. Acta Pol. Pharm. 2001, 58, 373-379. [PubMed]

11. Geetha, K.M.; Bindu, V.; Murugan, V. Antioxidant potential of Viscum articulatum burm. Chron. Young Sci. 2013, 4, 32-35. [CrossRef]

12. Li, H.Z.; Hou, Z.; Li, C.; Zhang, Y.; Shen, T.; Hu, Q.W.; Ren, D.M. Three pairs of diastereoisomeric flavanone glycosides from Viscum articulatum. Fitoterapia 2015, 102, 156-162. [CrossRef] [PubMed]

13. Li, Y.; Zhao, Y.L.; Huang, N.; Zheng, Y.T.; Yang, Y.P.; Li, X.L. Two New Phenolic Glycosides from Viscum articulatum. Molecules 2008, 13, 2500-2508. [CrossRef] [PubMed]

14. Leu, Y.L.; Kuo, S.M.; Hwang, T.L.; Chiu, S.T. The inhibition of superoxide anion generation by neutrophils from Viscum articulactum. Chem. Pharm. Bull. 2004, 52, 858-860. [CrossRef] [PubMed]

15. Wang, Y.K.; Zhang, X.; Chen, G.L.; Yu, J.; Yang, L.Q.; Gao, Y.Q. Antioxidant property and their free, soluble conjugate and insoluble-bound phenolic contents in selected beans. J. Funct. Foods 2016, 24, 359-372. [CrossRef]

16. Lewandowska, H.; Kalinowska, M.; Lewandowski, W.; Stępkowski, T.M.; Brzóska, K. The role of natural polyphenols in cell signaling and cytoprotection against cancer development. J. Nutr. Biochem. 2016, 32, 1-19. [CrossRef] [PubMed]

17. Laus, M.N.; Benedetto, N.A.D.; Caporizzi, R.; Tozzi, D.; Soccio, M.; Giuzio, L.; Vita, P.D.; Flagella, Z.; Pastore, D. Evaluation of Phenolic Antioxidant Capacity in Grains of Modern and Old Durum Wheat Genotypes by the Novel QUENCHER ABTs Approach. Plant Foods Hum. Nutr. 2015, 70, 207-214. [CrossRef] [PubMed]

18. Shahidi, F.; Yeo, J.D. Insoluble-Bound Phenolics in Food. Molecules 2016, 21, 1216-1237. [CrossRef] [PubMed]

19. Yu, J.; Vasanthan, T.; Temelli, F. Analysis of Phenolic Acids in Barley by High-Performance Liquid Chromatography. J. Agric. Food Chem. 2001, 49, 4352-4358. [CrossRef] [PubMed]

20. Chandrasekara, A.; Shahidi, F. Content of Insoluble Bound Phenolics in Millets and Their Contribution to Antioxidant Capacity. J. Agric. Food Chem. 2010, 58, 6706-6714. [CrossRef] [PubMed]

21. Rice-Evans, C.A.; Miller, N.J.; Paganga, G. Antioxidant properties of phenolic compounds. Trends Plant Sci. 1997, 2, 152-159. [CrossRef]

22. Chandrasekara, A.; Shahidi, F. Inhibitory Activities of Soluble and Bound Millet Seed Phenolics on Free Radicals and Reactive Oxygen Species. J. Agric. Food Chem. 2011, 59, 428-436. [CrossRef] [PubMed]

23. Köksal, E.; Bursal, E.; Gülçin, İ.; Korkmaz, M.; Çağlayan, C.; Gören, A.C.; Alwasel, S.H. Antioxidant activity and polyphenol content of Turkish thyme (Thymus vulgaris) monitored by liquid chromatography and tandem mass spectrometry. Int. J. Food Prop. 2017, 20, 514-525. [CrossRef]

24. Al-Rimawi, F.; Rishmawi, S.; Ariqat, S.H.; Khalid, M.F.; Warad, I.; Salah, Z. Anticancer Activity, Antioxidant Activity, and Phenolic and Flavonoids Content of Wild Tragopogon porrifolius Plant Extracts. Evid.-Based Complement. Altern. Med. 2016, 2016. [CrossRef] [PubMed]

25. Yuyen, P.T.; Xuan, T.D.; Khang, D.T.; Ahmad, A.; Quan, N.V.; Anh, T.T.A.; Anh, L.H.; Minh, T.N. Phenolic Compositions and Antioxidant Properties in Bark, Flower, Inner Skin, Kernel and Leaf Extracts of Castanea crenata Sieb. et Zucc. Antioxidants 2017, 6, 31. [CrossRef]

26. Song, F.L.; Gan, R.Y.; Zhang, Y.; Xiao, Q.; Kuang, L.; Li, H.B. Total Phenolic Contents and Antioxidant Capacities of Selected Chinese Medicinal Plants. Int. J. Mol. Sci. 2010, 11, 2362-2372. [CrossRef] [PubMed]

27. Albishi, T.; John, J.A.; Al-Khalifa, A.S.; Shahidi, F. Antioxidative phenolic constituents of skins of onion varieties and their activities. J. Funct. Foods 2013, 5, 1191-1203. [CrossRef]

28. Minh, T.N.; Khang, D.T.; Tuyen, P.H.; Minh, L.T.; Anh, L.H.; Quan, N.V.; Ha, P.T.T.; Quan, N.T.; Toan, N.P.; Elzaawely, A.A.; et al. Phenolic Compounds and Antioxidant Activity of Phalaenopsis Orchid Hybrids. Antioxidants 2016, 5, 31-42. [CrossRef] [PubMed]

29. Minh, T.N.; Tuyen, P.T.; Khang, D.T.; Quan, N.V.; Ha, P.T.T.; Quan, N.T.; Andriana, Y.; Fan, X.; Van, T.M.; Khanh, T.D.; et al. Potential Use of Plant Waste from the Moth Orchid (Phalaenopsis Sogo Yukidian "V3") as an Antioxidant Source. Foods 2017, 6, 85. [CrossRef] [PubMed] 
30. Issaad, F.Z.; Fernandes, I.P.G.; Enache, T.A.; Mouats, C.; Rodrigues, I.A.; Oliveira-Brett, A.M. Flavonoids in Selected Mediterranean Fruits: Extraction, Electrochemical Detection and Total Antioxidant Capacity Evaluation. Electroanalysis 2016, 29, 358-366. [CrossRef]

31. Hermans, N.; Cos, P.; Maes, L.; De, B.T.; Vanden, B.D.; Vlietinck, A.J.; Pieters, L. Challenges and Pitfalls in Antioxidant Research. Curr. Med. Chem. 2007, 14, 417-430. [CrossRef] [PubMed]

32. Herrera, E.; Jiménez, R.; Aruoma, O.I.; Hercberg, S.; Sánchez-garcía, I.; Fraga, C.; Serramajem, L.; Ngo, J.; Aranceta, J.; Solomons, N.W. Aspects of antioxidant foods and supplements in health and disease. Nutr. Rev. 2009, 67, S140-S144. [CrossRef] [PubMed]

33. Lou, S.N.; Lin, Y.S.; Hsu, Y.S.; Chiu, E.M.; Ho, C.T. Soluble and insoluble phenolic compounds and antioxidant activity of immature calamondin affected by solvents and heat treatment. Food Chem. 2014, 161, 246-253. [CrossRef] [PubMed]

34. Kumar, K.N.S.; Saraswathy, A.; Amerjothy, S.; Susan, T.; Ravishankar, B. Total Phenol Content and In Vitro Antioxidant Potential of Helicanthus elastica (Desr.) Danser-A Less-explored Indian Mango Mistletoe. J. Tradit. Complement. Med. 2014, 4, 285-288. [CrossRef] [PubMed]

35. Sulaiman, C.T.; Balachandran, I. Total Phenolics and Total Flavonoids in Selected Indian Medicinal Plants. Indian J. Pharm. Sci. 2012, 74, 254-258. [CrossRef] [PubMed]

36. Rahmawati, S.I.; Ishimaru, K.; Hou, D.X.; Hayashi, N. Antioxidant Activity and Phenolic Content of Mistletoe Extracts Following High-Temperature Batch Extraction. Food Sci. Technol. Res. 2014, 20, 201-206. [CrossRef]

37. Meng, Y.; Su, A.; Yuan, S.; Zhao, H.; Tan, S.; Hu, C.; Deng, H.; Guo, Y. Evaluation of Total Flavonoids, Myricetin, and Quercetin from Hovenia dulcis Thunb. As Inhibitors of $\alpha$-Amylase and $\alpha$-Glucosidase. Plant Foods Hum. Nutr. 2016, 71, 444-449. [CrossRef] [PubMed]

38. Chandrasekara, A.; Shahidi, F. Determination of antioxidant activity in free and hydrolyzed fractions of

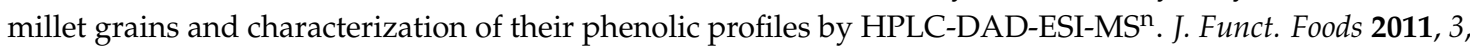
144-158. [CrossRef]

39. Singleton, V.L.; Rossi, J.A. Colorimetry of Total Phenolics with Phosphomolybdic-Phosphotungstic Acid Reagents. Am. J. Enol. Vitic. 1965, 16, 144-158. [CrossRef]

40. Kern, S.M.; Bennett, R.N.; Mellon, F.A.; Kroon, P.A.; Garcia-Conesa, M. Absorption of hydroxycinnamates in humans after high-bran cereal consumption. J. Agric. Food Chem. 2003, 51, 6050-6055. [CrossRef] [PubMed]

41. Chandrasekara, A.; Naczk, M.; Shahidia, F. Effect of processing on the antioxidant activity of millet grains. Food Chem. 2012, 133, 1-9. [CrossRef]

42. Benzie, I.F.F.; Strain, J.J. The Ferric Reducing Ability of Plasma (FRAP) as a Measure of "Antioxidant Power": the FRAP Assay. Anal. Biochem. 1996, 239, 70-76. [CrossRef] [PubMed]

43. Villanueva-Carvajal, A.; Bernal-Martínez, L.R.; García-Gasca, M.T.; Dominguez-Lopez, A. In vitro gastrointestinal digestion of Hibiscus sabdariffa L.: The use of its natural matrix to improve the concentration of phenolic compounds in gut. Food Sci. Technol. 2013, 51, 260-265. [CrossRef]

44. Wettasinghe, M.; Shahidi, F. Scavenging of reactive-oxygen species and DPPH free radicals by extracts of borage and evening primrose meals. Food Chem. 2000, 70, 17-26. [CrossRef]

45. Hatano, T.; Kagawa, H.; Yasuhara, T.; Okuda, T. Two new flavonoids and other constituents in licorice root: Their relative astringency and radical scavenging effects. Chem. Pharm. Bull. 1988, 36, 2090-2097. [CrossRef] [PubMed]

46. Re, R.; Pellegrini, N.; Proteggente, A.; Pannala, A.; Yang, M.; Riceevans, C. Antioxidant activity applying an improved ABTS radical cation decolorization assay. Free Radic. Biol. Med. 1999, 26, 1231-1237. [CrossRef]

Sample Availability: Samples of the plant materials and extracts are available from the authors. 